\title{
The caspase-independent algorithm of programmed cell death in Leishmania induced by baicalein: the role of LdEndoG, LdFEN-1 and LdTatD as a DNA 'degradesome'
}

\author{
S BoseDasgupta ${ }^{1}$, BB Das ${ }^{2}$, S Sengupta ${ }^{1}$, A Ganguly ${ }^{1}$, A Roy ${ }^{1}$, S Dey ${ }^{3}$, G Tripathi ${ }^{4}$, B Dinda ${ }^{5}$ and HK Majumder ${ }^{*, 1}$
}

In the post-genomic perspective, the quest of programmed cell death (PCD) mechanisms in kinetoplastid parasites lies in the identification and characterization of cell death executer proteins. Here, we show that baicalein (BLN), a potent topoisomerase IB inhibitor, generates an oxidative stress in the parasites leading to altered physiological and morphological parameters, which are characteristic of PCD. For the first time we elucidate that, caspase-independent activation of a novel effector molecule, endonuclease G (LdEndoG), mediates BLN-induced cell death. Functional characterization of LdEndoG identifies Flap endonuclease-1 (LdFEN-1) and LdTatD-like nuclease as other effector molecules. BLN treatment translocates LdEndoG from mitochondria to nucleus, where it forms separate complexes with LdFEN-1 and LdTatD to constitute a DNA 'degradesome' unique to these parasites. Conditional antisense knockdown of LdEndoG provides protection against PCD. This knowledge paves the path toward a better understanding of the PCD pathway in simpler systems, which could be exploited in antileishmanial chemotherapy.

Cell Death and Differentiation (2008) 15, 1629-1640; doi:10.1038/cdd.2008.85; published online 20 June 2008

Programmed cell death (PCD) involves genetically controlled mechanisms that eliminate unnecessary cells and regulate growth and development of an organism. Type I PCD involves changes in plasma membrane permeability, DNA fragmentation and formation of apoptotic bodies, whereas type II PCD involves autophagy. ${ }^{1}$ Physiological imbalances activate endonucleases through caspase-like proteases ${ }^{2}$ (caspasedependent pathway) or directly ${ }^{3}$ (caspase-independent pathway). In higher eukaryotes, activated caspase-3 activates caspase-activated DNases ${ }^{4}$ (CADs). Endonuclease $\mathrm{G}^{3}$ (EndoG) and AIF comprise caspase-independent effector endonucleases. Cytotoxic agents induce oxidative stress and cause nuclear translocation of EndoG, which thereby induce DNA fragmentation, and PCD. ${ }^{5}$

In Leishmania, PCD helps in altruistic growth control and organizes them into clonal populations. ${ }^{6}$ It maximizes their biological fitness and facilitates their adaptation to the digenic life cycle. ${ }^{1}$ Topoisomerases are DNA manipulators that relieve the torsional strain in DNA built up during vital cellular processes. Advent of chemoresistance has made leishmaniasis a significant health problem. Hence the unusual bisubunit topoisomerase IB of kinetoplastids is an attractive therapeutic target. ${ }^{7}$ In higher eukaryotes, 'DNA sensors' recognize inhibitor trapped topol-DNA cleavable complex and activate Bax to subtly permeabilize the mitochondrial outer membrane. This generates an oxidative stress and causes nascent cytochrome $c$ release. ${ }^{8}$ Cytochrome $c$ forms the 'apoptosome' and also binds to inositol triphosphate receptors in the membranes of intracellular calcium pools ${ }^{9}$ to release $\mathrm{Ca}^{2+}$ into the cytosol. In caspase-independent PCD, the increase in intracellular calcium increases mitochondrial calcium and causes further mitochondrial membrane depolarization, reactive oxygen species (ROS) generation and activation of endonucleases. ${ }^{5}$ In Leishmania, the potent topoisomerase IB inhibitor camptothecin (CPT) is known to induce DNA degradation and PCD. ${ }^{10}$ Flavones are polyphenolic compounds with profound pharmacological properties. Baicalein (BLN) or 5,6,7-trihydroxy flavone stabilizes the topoisomeraselB-DNA complex and kills both the wild-type and CPT-resistant parasites. ${ }^{11}$

Here, we show that BLN induces caspase-independent PCD of the parasites. Elucidating the PCD mechanisms in these unicellular organisms lies in characterizing death executer proteins. BLN-induced physiological and

\footnotetext{
${ }^{1}$ Molecular Parasitology Laboratory, Infectious Diseases and Immunology Division, Indian Institute of Chemical Biology, Kolkata, India; ${ }^{2}$ Laboratory of Molecular Pharmacology, Centre for Cancer Research, National Cancer Institute, Bethesda, MD, USA; ${ }^{3}$ Electron Microscopy Division, Indian Institute of Chemical Biology, Kolkata, India; ${ }^{4}$ Division of Cellular Physiology, Indian Institute of Chemical Biology, Kolkata, India and ${ }^{5}$ Department of Chemistry, Tripura University, Suryamaninagar, Tripura, India

*Corresponding author: HK Majumder, Molecular Parasitology Laboratory, Indian Institute of Chemical Biology, 4, Raja SC Mullick Road, Kolkata 700 032, West Bengal, India. Tel: + 910332412 3207; Fax: + 910332473 5197; E-mail: hkmajumder@iicb.res.in

Keywords: Leishmania; baicalein; topoisomerase IB; caspase-independent; LdEndoG

Abbreviations: PCD, programmed cell death; BLN, baicalein; PI, propidium iodide; ROS, reactive oxygen species; CPT, camptothecin; NAC, N-acetyl cysteine; TSH, trypanothione; BAPTA, 1,2-bis (o-aminophenoxy)ethane- $N, N, N, N$-tetraacetic acid; ATA, aurin tricarboxylic acid; $\Delta \psi_{\mathrm{m}}$, mitochondrial transmembrane potential; FITC, fluorescein thiocyanate; $\mathrm{H}_{2}$ DCFDA, 5-(and -6)-chloromethyl-2', $7^{\prime}$-dichlorodihydrofluorescein diacetate acetyl ester; FEN-1, flap endonuclease-1; CCCP, carbonyl cyanide $m$-chlorophenyl hydrazone; zVAD-fmk, Val-Ala-Asp-fluoromethyl ketone; TUNEL, terminal deoxynucleotidyltransferase enzyme-mediated dUTP end labeling; DMSO, dimethyl sulfoxide
}

Received 27.2.08; revised 03.4.08; accepted 05.5.08; Edited by S Kumar; published online 20.6.08 
morphological imbalance causes nuclear translocation of mitochondrial LdEndoG, which thereby forms separate complexes with LdFEN-1 (flap endonuclease-1; a DNA repair protein) and LdTatD-like nucleases (a prokaryotic nuclease) to degrade DNA. Recombinant LdEndoG has been functionally characterized in vitro. BLN treatment of LdEndoGdownregulated parasites fails to exhibit DNA fragmentation and PCD. Taken together, our results provide the first insight into the mechanism of caspase-independent PCD in Leishmania involving a previously uncharacterized DNA 'degradesome' comprising of LdEndoG and complexes, LdEndoG/LdFEN-1 and LdEndoG/LdTatD-like nuclease.

\section{Results}

BLN-induced inhibition of promastigote growth occurs via an oxidative stress-induced PCD pathway. Treatment of promastigotes with BLN $(10 \mu \mathrm{M})$ causes $73 \%$ growth inhibition in $4 \mathrm{~h}$ and $89 \%$ inhibition in $6 \mathrm{~h}$ (Figure $1 \mathrm{a})$. BLN is a more potent inhibitor of bi-subunit topoisomerase IB compared to CPT. ${ }^{11}$ Immunoband depletion ${ }^{12}$ and TopBioassay show that BLN stabilizes the topol-DNA cleavable complex in vivo (Supplementary Information I), which thereby kills the parasites.

Oxygen uptake was measured in the BLN-treated and untreated $(0.2 \%$ dimethyl sulfoxide (DMSO)) parasites with time. ${ }^{10}$ Leishmania donovani promastigotes consume oxygen at the rate of $83 \pm 8 \mathrm{nmol} / \mathrm{min} / \mathrm{mg}$ of protein, which remains unchanged for $6 \mathrm{~h}$. BLN treatment decreases oxygen consumption rate to $53 \pm 5 \mathrm{nmol} / \mathrm{min} / \mathrm{mg}$ of protein in $1 \mathrm{~h}$ and to $13 \pm 1.7 \mathrm{nmol} / \mathrm{min} / \mathrm{mg}$ of protein in $4 \mathrm{~h}$ (Figure $1 \mathrm{~b}$ ). This $87 \%$ reduction in oxygen consumption in $4 \mathrm{~h}$ indicates that BLN induces oxidative stress in the parasites, which leads to cell death.

The mode of cell death in BLN- and DMSO-treated parasites was identified by fluorescein isothiocyanate (FITC)-annexinV and propidium iodide (PI) staining. ${ }^{10}$ Parasites treated with $5 \mathrm{mM} \mathrm{H}_{2} \mathrm{O}_{2}$ served as a positive control. ${ }^{10}$ Externalization of phosphatidyl serine (stained by annexinV) and presence of impermeant cell membrane (negative $\mathrm{PI}$ staining) are hallmarks of PCD. But necrotic cells being permeant to PI show positive nuclear PI staining and therefore discriminates itself from PCD-induced parasites. Flow cytometry shows that $94 \%$ of DMSO-treated parasites were both $\mathrm{PI}$ and annexinV negative, while $82 \%$ of $\mathrm{H}_{2} \mathrm{O}_{2}$-treated parasites were annexinV positive. BLN (5 and $10 \mu \mathrm{M}$ ) treatment caused 32.5 and $72 \%$ annexinV-positive parasites, respectively (Figure 1c). Confocal microscopy shows the appearance of ring-like green fluorescence of FITC-annexinV for the BLN-treated parasites, thereby indicating externalization of phosphatidyl serine (Figure 1d).

As BLN-induced phophatidyl serine externalization hints toward induction of PCD, we observed the changes in the ultrastructure of the $L$. donovani promastigotes through electron microscopy ${ }^{10}$ (Figure 1e). The slender, flagellated promastigotes become round with appearance of vacuoles and lipid bodies. DMSO-treated parasites retain the normal nuclear architecture, whereas BLN-treated parasites exhibit a condensed or marginated chromatin and fragmented nucleus.
The plasma membrane was impermeant but blebbed. As PCD involves endonuclease-mediated DNA fragmentation, we pretreated parasites with general endonuclease inhibitors aurin tricarboxylic acid (ATA). Thereafter BLN treatment of these parasites exhibited intact membrane and nuclear structure.

BLN-induced oxidative stress causes loss of mitochondrial membrane potential, generation of ROS and DNA fragmentation in the parasites. The morphological changes in PCD result from several physiological imbalances that arise inside the parasites. BLN-induced oxidative stress disrupts the intracellular cation homeostasis of the parasites. Intracellular $\mathrm{K}^{+}$decreases, whereas intracellular $\mathrm{Ca}^{2+}$ increases and thereby raises mitochondrial calcium ${ }^{13}$ (Supplementary Information II).

Mitochondrial $\mathrm{Ca}^{2+}$ overload depolarizes the mitochondrial membrane. Using BD mitosensor reagent, we monitored mitochondrial membrane potential $\left(\Delta \psi_{\mathrm{m}}\right)$. Fall in the mitochondrial membrane potential increases the green fluorescence intensity. Flow cytometry shows that BLN-treated parasites exhibit a right shift in the FL-1 channel (Figure 2a). The mitochondrial uncoupler CCCP (carbonyl cyanide $m$-chlorophenyl hydrazone; $1 \mu \mathrm{M}$ ) causes a greater right shift and served as the positive control. Hence a loss in $\Delta \psi_{\mathrm{m}}$ was clearly evident. Parasites pretreated with the antioxidant, $\mathrm{N}$-acetyl cysteine (NAC) or intracellular $\mathrm{Ca}^{2+}$ chelator BAPTA-AM (1,2-bis(o-aminophenoxy)ethane- $N, N, N$, $N$-tetraacetic acid) or ATA prior to BLN treatment prevents the rapid loss of $\Delta \psi_{\mathrm{m}}$. Hence, BLN-induced cellular stress alters the calcium homeostasis, which thereby induces loss of $\Delta \psi_{\mathrm{m}}$. Permeabilization of mitochondrial outer membrane causes increased release of cytochrome $c$ into the cytoplasm with time (Figure $2 b$ ). Pretreatment of the parasites with NAC, BAPTA-AM or ATA decreases the rate of cytochrome $c$ release. But pretreatment of the parasites with the caspase inhibitor, zVAD-fmk (Val-Ala-Asp-fluoromethyl ketone) or the metacaspase inhibitor, antipain ${ }^{14,15}$ (a general trypsin-like protease inhibitor) could not prevent rapid cytochrome $c$ release.

Loss of $\Delta \psi_{\mathrm{m}}$ induces ROS formation inside the parasites, which was measured spectrofluorimetrically by the conversion of $\mathrm{H}_{2}$ DCFDA (5-(and -6)-chloromethyl-2', $7^{\prime}$-dichlorodihydrofluorescein diacetate acetyl ester) to fluorescent 2,7-dichlorofluorescein. ${ }^{13}$ BLN treatment generated a fivefold higher amount of ROS (compared to DMSO treatment) inside the parasites (Figure 2c). In comparison, pretreating parasites with NAC or ATA prior to BLN treatment reduced the level of ROS generation by 50 and $25 \%$, respectively. Confocal images of DMSO- or BLN-treated parasites loaded with $\mathrm{H}_{2}$ DCFDA clearly support the spectrofluorimetric data (Figure 2d). Generation of ROS in the parasites causes concomitant decrease in the cellular trypanothione (TSH) ${ }^{10}$ levels (Supplementary Information III).

Above physiological imbalances activate endonucleases that degrade cellular DNA, which is characteristic of PCD. So we estimated the extent of DNA fragmentation ${ }^{7}$ in parasite after different treatments (Figure 2e). DMSO-treated parasites exhibited a single genomic DNA band, whereas BLN-treated parasites showed a laddering pattern indicative 


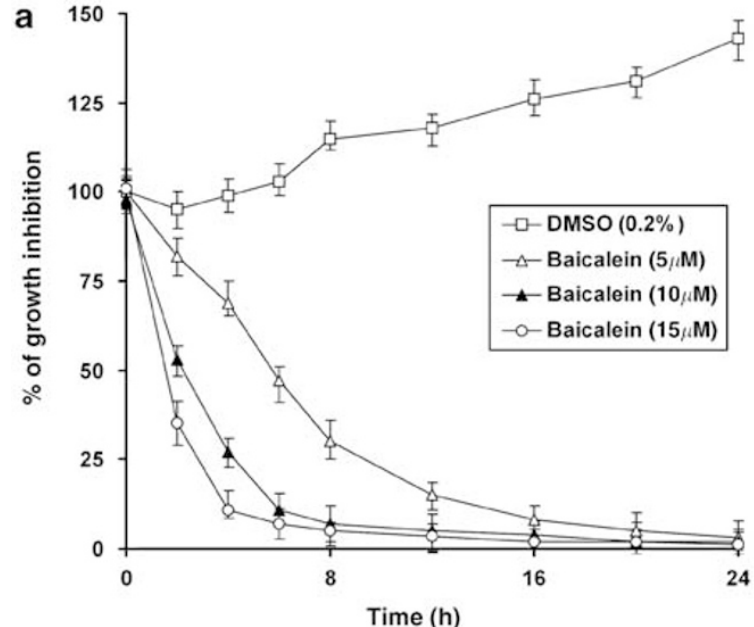

c

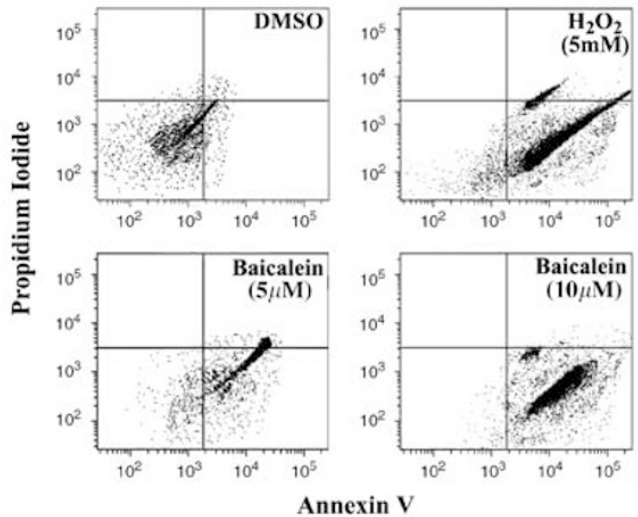

d

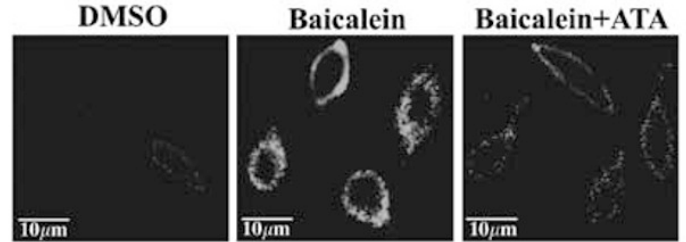

b

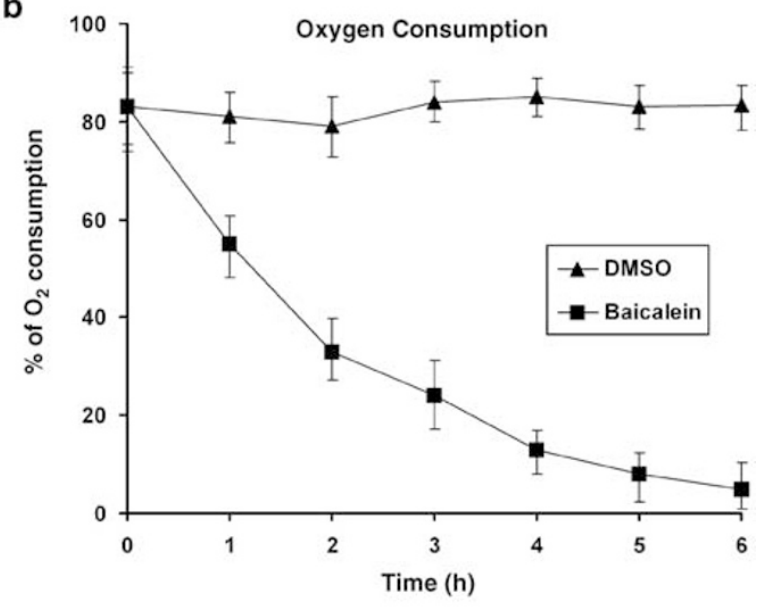

e
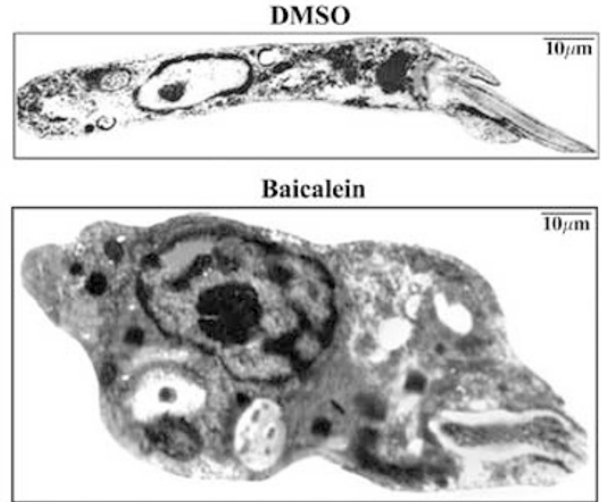

Baicalein + ATA

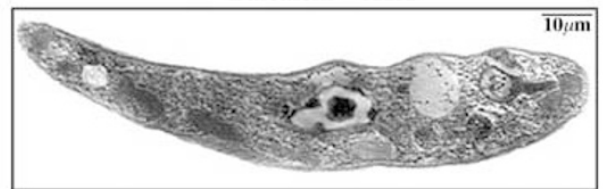

Figure 1 Cytotoxicity analysis and morphological changes caused by baicalein. (a) Promastigotes were cultured in the presence of $0.2 \% \mathrm{DMSO}(\square)$ or $5 \mu \mathrm{M}(\triangle) 10 \mu \mathrm{M}$ $(\mathbf{\Delta})$ and $15 \mu \mathrm{M}(\mathrm{O}) \mathrm{BLN}$. Aliquots were taken at intervals and percentage of viable promastigotes was calculated. Values were taken in triplicate averaged and plotted against time. (b) Percentage of oxygen consumption was measured for $0.2 \%$ DMSO $(\mathbf{\Delta})$ - or $10 \mu \mathrm{M} \mathrm{BLN}(\boldsymbol{\square})$-treated parasites. Data represent means \pm S.D. ( $n=3$ ). (c) Flow cytometric analysis of promastigote death through $\mathrm{PCD} /$ necrotic processes. Parasites were stained with FITC-annexinV and propidium iodide after treatment with $0.2 \%$ DMSO, BLN $(5$ and $10 \mu \mathrm{M})$ and $5 \mathrm{mM} \mathrm{H}_{2} \mathrm{O}_{2}$. (d) Confocal microscopic images of the promastigotes treated with $0.2 \%$ DMSO, $10 \mu \mathrm{M}$ BLN alone or along with $50 \mu \mathrm{M}$ ATA. BLNtreated parasites undergo PCD as evident from positive FITC-annexinV staining of externalized phosphatidyl serine (PS). Treatment with ATA inhibits cellular endonucleases upon BLN treatment and prevents PS externalization. (e) Electron microscopic images of promastigotes treated with $0.2 \%$ DMSO, $10 \mu \mathrm{M} \mathrm{BLN}$ alone or along with $50 \mu \mathrm{M}$ ATA. Magnification: $\times 20000$; Nu, nucleus; $\mathrm{K}$, kinetoplast; $\mathrm{CMC}$, condensed and marginated chromatin; FN, fragmented nucleus; $\mathrm{MB}$, membrane blebbing (A colour version of this figure is available online)

of DNA fragmentation. $\mathrm{H}_{2} \mathrm{O}_{2}$-treated parasites exhibit more prominent ladders. BLN treatment of parasites along with $50 \mu \mathrm{M}$ ATA caused $40 \%$ reduction in DNA fragmentation in $4 \mathrm{~h}$.

BLN-induced physiological imbalance leading to time course increase in DNA fragmentation involves DNases other than caspase-activated DNases. The extent of DNA fragmentation in BLN-treated parasites was estimated using an ELISA-based kit. $^{12} \mathrm{~A}$ time course increase in BLNinduced DNA fragmentation reached saturation in $6 \mathrm{~h}$ (Figure 3a). DMSO treatment failed to degrade DNA while
CPT $(10 \mu \mathrm{M})$ induced considerable DNA fragmentation. ${ }^{10}$ Parasites pre-incubated with $25 \mu \mathrm{M}$ zVAD-fmk prior to CPT treatment prevented DNA degradation. But pretreatment of the parasites with zVAD-fmk prior to BLN or CPT treatment prevented DNA degradation only for the CPT-treated parasites. This indicated that caspases had no role in BLNinduced PCD. Leishmania parasites exhibit stress-induced activation of metacaspases, which thereby induce DNA fragmentation. ${ }^{14}$ Pretreatment of parasites with antipain ${ }^{15}$ prior to BLN treatment partially reduced the extent of DNA fragmentation. As inhibition of proteases activating endonucleases could not prevent DNA fragmentation, we 
a
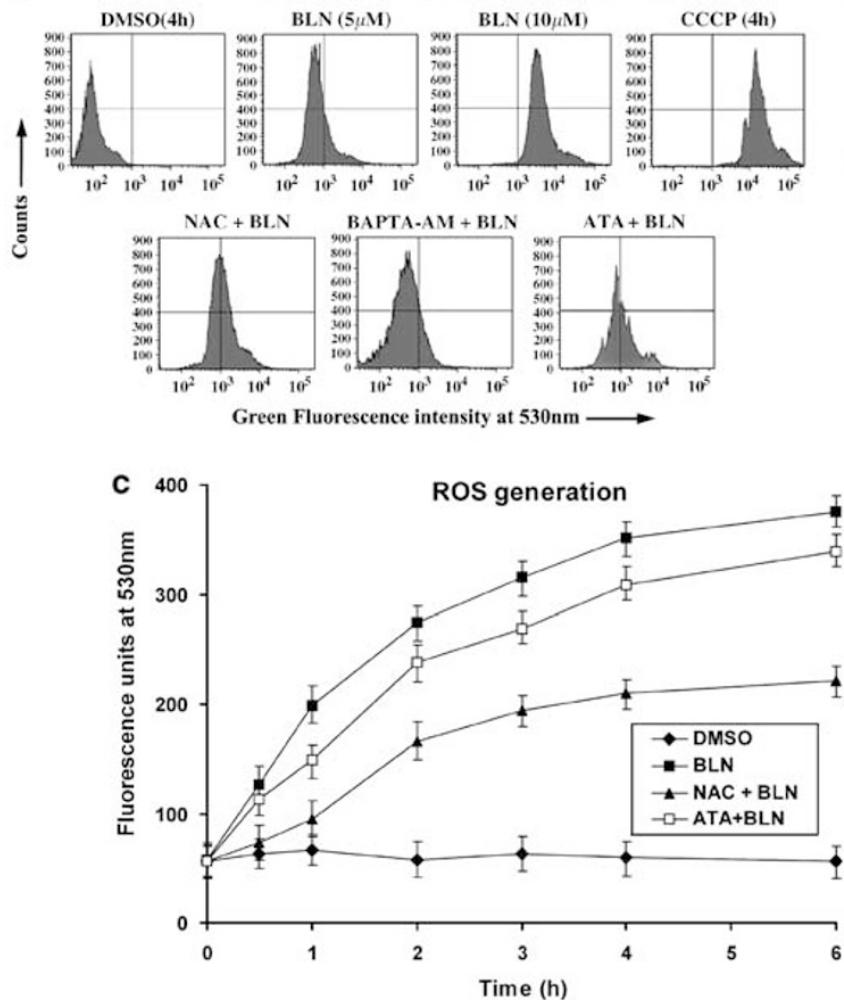

d

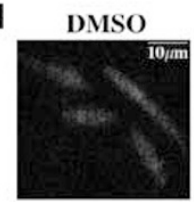

b
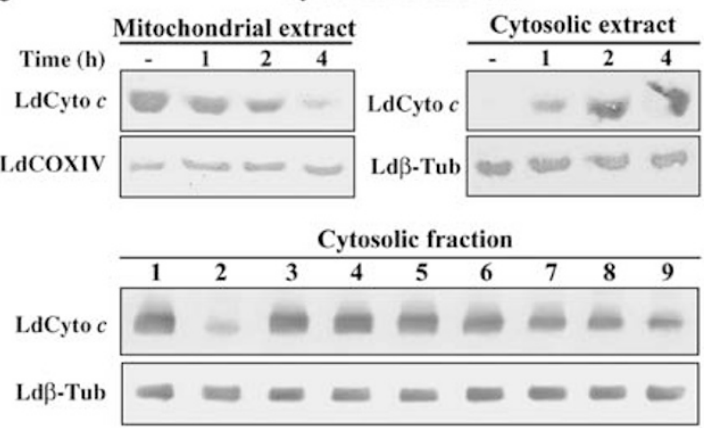

e

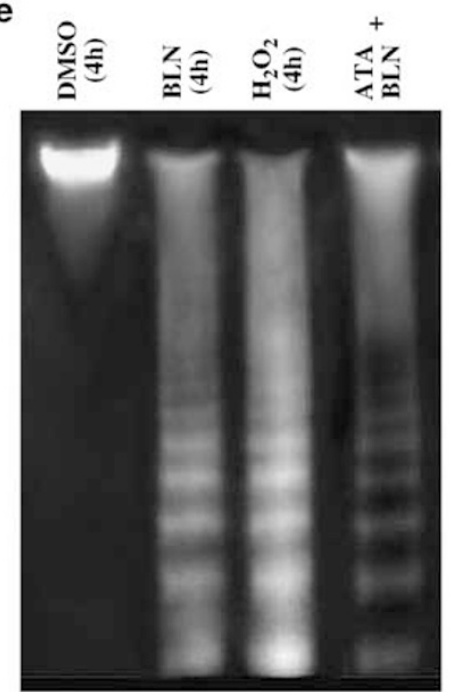

Figure 2 Physiological changes caused by BLN treatment. (a) Flow cytometric analysis of mitochondrial membrane potential. Parasites were treated with $0.2 \%$ DMSO, BLN $(5$ or $10 \mu \mathrm{M}), \operatorname{CCCP}(1 \mu \mathrm{M})$ or with $10 \mu \mathrm{M}$ BLN after pretreatment with NAC, BAPTA-AM or ATA. Thereafter promastigotes were incubated with BD mitosensor reagent and the green fluorescence intensity was monitored using flow cytometry. (b) Immunoblot analysis of cytochrome $c$. Upper panel shows immunoblot using anti-cytochrome $c$ antibody, for mitochondrial and cytoplasmic fractions from parasite aliquots taken at given intervals after BLN $(10 \mu \mathrm{M})$ treatment. Immunoblots of LdCOXIV and Ld $\beta$-tubulin served as loading controls for the mitochondrial and cytosolic fractions, respectively. Lower panel shows immunoblot for cytochrome $c$ in total cell lysate (lane 1), cytosolic extracts for $0.2 \%$ DMSO-treated parasites (lane 2), BLN (10 $\mu \mathrm{M}$ ) treatment for $3 \mathrm{~h}$ (lane 3), BLN-treated parasites after pretreatment with $25 \mu \mathrm{M}$ zVAD-fmk (lane 4), $2 \mu \mathrm{M}$ antipain (lane 5), $10 \mu \mathrm{M}$ cyclosporine A (lane 6), $50 \mu \mathrm{M}$ ATA (lane 7), $20 \mathrm{mM} \mathrm{NAC} \mathrm{(lane} \mathrm{8)} \mathrm{or} 25 \mu \mathrm{M}$ BAPTA-AM (lane 9). Immunoblot using anti- $\beta$-tubulin antibody served as the loading control. (c) Measurement of ROS generation for the promastigotes treated with $0.2 \%$ DMSO or $10 \mu \mathrm{M} \mathrm{BLN}$ alone or after pre-incubation with NAC or ATA. After incubation with $\mathrm{H}_{2}$ DCFDA the fluorescence intensity was measured at $530 \mathrm{~nm}$. Values were taken in triplicate averaged and plotted against time. (d) Confocal microscopic images of promastigotes treated with $0.2 \%$ DMSO or $10 \mu \mathrm{M}$ BLN alone or after pre-incubation with NAC or ATA. (e) DNA ladder assay of parasites treated with $0.2 \%$ DMSO, $10 \mu \mathrm{M} \mathrm{BLN}, 5 \mathrm{mM} \mathrm{H}_{2} \mathrm{O}_{2}$ and $10 \mu \mathrm{M} \mathrm{BLN}$ along with $50 \mu \mathrm{M}$ ATA (A colour version of this figure is available online)

pretreated the parasites with $\mathrm{ATA}{ }^{5} \mathrm{~A}$ considerable reduction in BLN-induced DNA fragmentation was observed.

Terminal deoxynucleotidyltransferase enzyme-mediated dUTP end labeling (TUNEL) assays helped to visualize the efficacy of these inhibitors in preventing BLN-induced DNA fragmentation. ${ }^{10}$ Figure $3 \mathrm{~b}$ and $\mathrm{c}$ shows the time course increase $(44 \%$ in $2 \mathrm{~h}$ and $87 \%$ in $4 \mathrm{~h}$ ) in DNA fragmentation upon BLN treatment as evident from the merged yellow fluorescence of green fluorescein-dUTP and red PI counterstain (A colour version of this figure is available online). Both zVAD-fmk and antipain could not prevent BLN-induced DNA fragmentation, hence parasites were TUNEL positive (83 and $78 \%$, respectively). Parasites pretreated with ATA prior to BLN treatment showed reduced (19\%) TUNEL-positive parasites as it inhibits the BLN-activated endonucleases.
Parasites treated with $10 \mu \mathrm{M} \mathrm{CPT}$ alone or after pretreatment with zVAD-fmk ${ }^{10}$ caused 73 and $17 \%$ parasites to be TUNEL positive. Thus, BLN-induced oxidative stress activates endonucleases independent of caspase-like proteins or metacaspases in these parasites.

BLAST analysis of the $L$. major genome yielded ORFs corresponding to mammalian EndoG (LmjF10.0610), a FEN-1 homolog (LmjF27.0250), TatD-like nuclease ${ }^{5,16,17}$ (LmjF11.1280) and other nucleases, ${ }^{18}$ all having implications in caspase-independent death pathways. Therefore, we sought to characterize LdEndoG of Leishmania.

Purification and characterization of recombinant Leishmania EndoG. The 1509 bp putative EndoG ORF was amplified by RT-PCR from total RNA of $L$. donovani, 
a

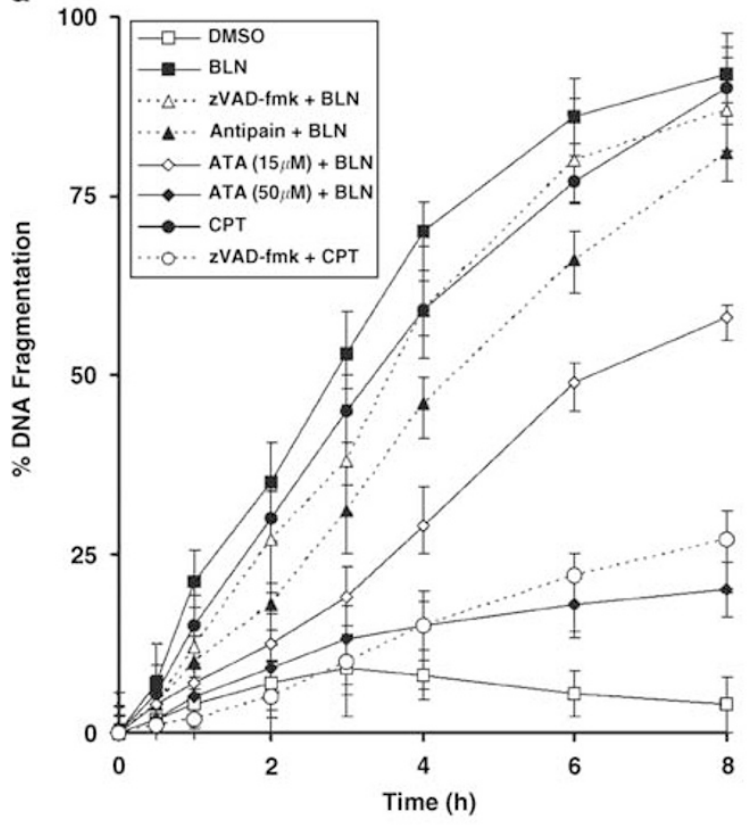

b

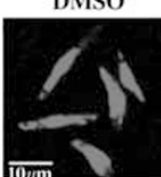

BLN + Antipain

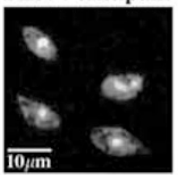

BLN (2h)
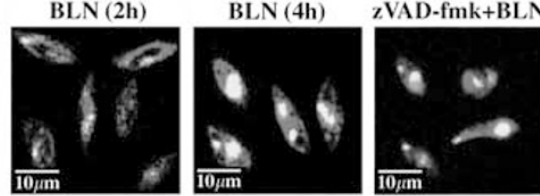

$\mathrm{BLN}+\mathrm{ATA}$

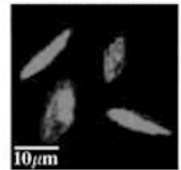

CP'

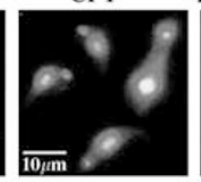

zVAD-fmk+CPT

C

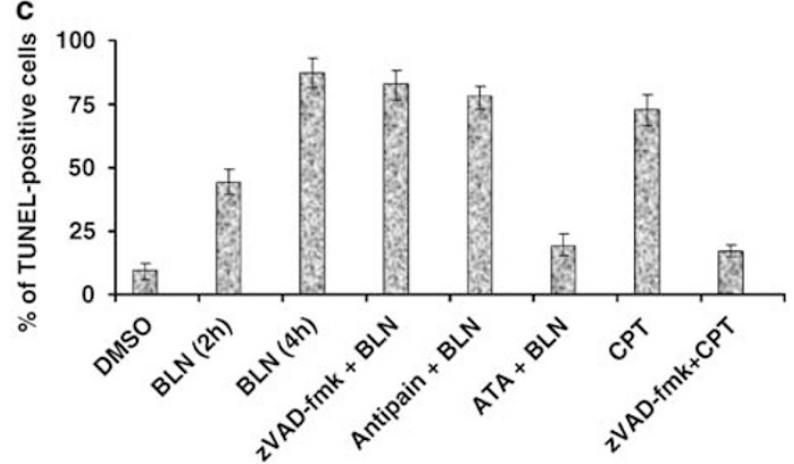

Figure 3 Extent of genomic DNA fragmentation upon BLN treatment. (a) Parasites were treated with $10 \mu \mathrm{M}$ BLN alone ( $\mathbf{\square}$ ) or after pre-incubation with $25 \mu \mathrm{M}$ zVAD-fmk $(\Delta), 2 \mu \mathrm{M}$ antipain $(\mathbf{\Delta})$ and ATA, $15 \mu \mathrm{M}(\diamond)$ and $50 \mu \mathrm{M}(\diamond)$. As negative control, parasites were also treated with $0.2 \%$ DMSO $(\square)$, whereas for positive control treatment with $10 \mu \mathrm{M}$ CPT alone or after pre-incubation with $25 \mu \mathrm{M}$ zVAD-fmk was carried out. Values were obtained from the MULTISCAN EX readings at $405 \mathrm{~nm}$. The relative percentage (with respect to samples treated with micrococcal nuclease and normalized to percentage values) was plotted as units of time. Data represent means \pm S.D. $(n=3)$. (b) BLN-induced DNA fragmentation was visualized in the promastigotes by TUNEL assay. Parasites were treated with $0.2 \%$ DMSO, $10 \mu \mathrm{M}$ BLN for 2 and $4 \mathrm{~h}$ respectively. BLN treatment was also carried out after pre-incubation with $25 \mu \mathrm{M}$ zVAD-fmk, $2 \mu \mathrm{M}$ antipain or $50 \mu \mathrm{M} \mathrm{ATA}$. CPT (10 $\mu \mathrm{M}$ ) treatment alone or after pre-incubation with $25 \mu \mathrm{M}$ zVAD-fmk served as a positive control. (c) Graphical representation of the percentage of TUNEL-positive nuclei as observed under the microscope. Mean values for three sets of 200 parasites each were plotted (A colour version of this figure is available online)

cloned in pGEX-4T vector and transformed into Escherichia coli, Rosetta strain. ${ }^{19}$ Recombinant LdEndoG was either eluted as GST-LdEndoG using reduced glutathione or as LdEndoG using FactorX by cleaving GST tag. Figure $4 \mathrm{a}$ shows that GST-LdEndoG and LdEndoG were purified to essential homogeneity. The molecular weight of GSTLdEndoG was observed to be $79 \mathrm{kDa}$, whereas that of LdEndoG alone was $53 \mathrm{kDa}$.

To establish the purified protein as a nuclease, we carried out DNA zymography ${ }^{18}$ (SDS-DNA-PAGE). Both GSTLdEndoG and LdEndoG alone were electrophoresed in $10 \%$ SDS-PAGE containing sheared calf thymus DNA. The gel was incubated in a buffer containing ethidium bromide (EtBr). Figure $4 \mathrm{~b}$ shows degradation of DNA around $53 \mathrm{kDa}$, corresponding to LdEndoG in lanes 6-9 and negligible extent of DNA degradation around $79 \mathrm{kDa}$, corresponding to GST-LdEndoG in lane 4.

Recombinant LdEndoG gradually nicks and thereafter completely digests pGEM4Z plasmid (Figure 4c). In the presence of $5 \mathrm{mM} \mathrm{H} \mathrm{H}_{2} \mathrm{O}_{2}$ (representing oxidative stress conditions), LdEndoG fully retains its nuclease activity. ATA $(50 \mu \mathrm{M})$ could completely inhibit the in vitro nuclease activity of LdEndoG. When LdEndoG was incubated with isolated nuclei from DU145 cell lines, nucleosomal DNA fragmentation was observed (Figure 4d). Addition of $5 \mathrm{mM} \mathrm{H}_{2} \mathrm{O}_{2}$ had no effect on DNA laddering but $50 \mu \mathrm{M}$ ATA potently inhibited DNA fragmentation. These results strongly indicate that
LdEndoG is an ATA-inhibitable DNase that can induce nucleosomal DNA fragmentation under severe oxidative stress conditions.

BLN-induced oxidative stress activates LdEndoG and triggers its nuclear translocation, whereas knock down of LdEndoG slows BLN-induced cell death. Figure $5 \mathrm{~A}$, a shows that in DMSO-treated parasites, green FITC fluorescence of LdEndoG merges with red fluorescence of MitoTracker, thereby indicating its mitochondrial localization. Figure $5 \mathrm{~A}, \mathrm{~b}$ shows that in BLN-treated parasites, FITC fluorescence of LdEndoG merges with blue fluorescence of DAPI in the nucleus. Hence, BLN-induced oxidative stress depolarizes the mitochondrial membrane and forms mitochondrial transition pores. ${ }^{20} \mathrm{LdEndoG}$ translocates to the cytoplasm through these pores and enters the nucleus to fragment the nuclear DNA. ${ }^{21}$ Immunoblotting with antiLdEndoG for mitochondrial and nuclear extracts prepared from parasites shows gradual translocation of LdEndoG to the nucleus with time upon BLN treatment (Figure 5B). The equal band intensities corresponding to LdCOXIV for the mitochondrial extracts and LdHistone $\mathrm{H} 1$ for the nuclear extracts serve as loading controls.

Tetracycline (Tet)-induced production of antisense LdEndoG RNA in antiEg (anti-LdEndoG) transfectants downregulates $L d E n d o G$ RNA in vivo (Supplementary information III). Control mRNA of COXIV was not affected (data 


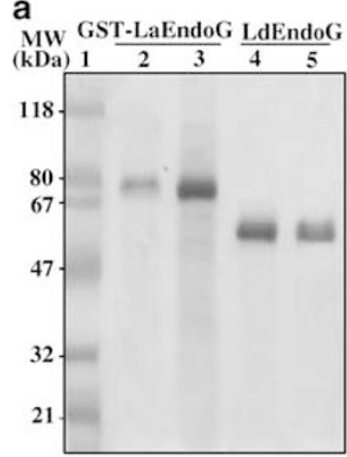

b

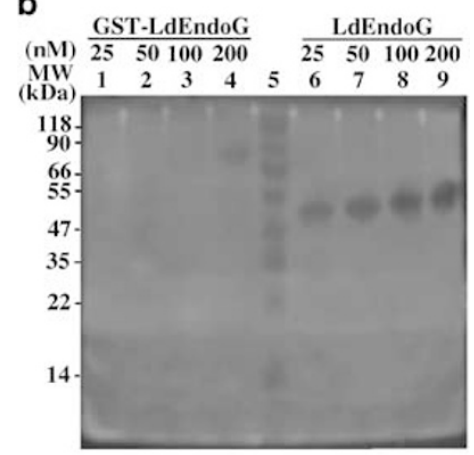

C

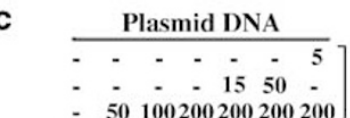

d

$\mathrm{H}_{2} \mathrm{O}_{2}(\mathrm{mM})$

ATA $(\mu \mathrm{M})$

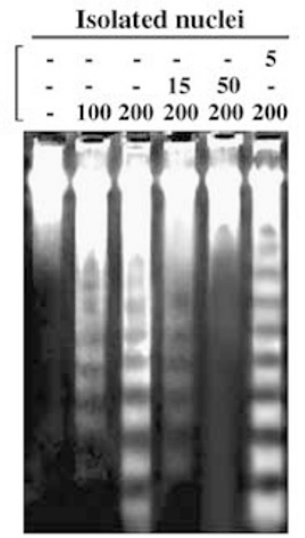

Figure 4 Purification and characterization of LdEndoG. (a) SDS-PAGE analysis of purified, $79 \mathrm{kDa}$ GST-LdEndoG (lanes 2 and 3) and $53 \mathrm{kDa}$ LdEndoG (lanes 4 and 5). (b) SDS-DNA-PAGE analysis of GST-LdEndoG (lanes 1-4) and LdEndoG (lanes 6-9) at concentrations (nanomolar) as indicated. (c) Endonuclease activity of recombinant LdEndoG in vitro using plasmid DNA. Lane 1, control plasmid DNA. Lanes 2-4, plasmid incubated with 50, 100 and $200 \mathrm{nM}$ LdEndoG. Lanes 5 and 6, plasmid incubated with $200 \mathrm{nM}$ LdEndoG in the presence of 15 and $50 \mu \mathrm{M}$ ATA. Lane 7, plasmid incubated with $200 \mathrm{nM} \mathrm{LdEndoG}$ in the presence of $5 \mathrm{mM} \mathrm{H}_{2} \mathrm{O}_{2}$. (d) Same as (c) but using nuclei, isolated from DU145 cells, instead of plasmid DNA and lacks the $50 \mathrm{nM}$ incubation in lane 2

not shown). LdEndoG level became undetectable after $24 \mathrm{~h}$ of Tet induction compared to equal levels for the LdCOXIV control (Figure 5C). BLN was added to parasites after $24 \mathrm{~h}$ of Tet-induced or uninduced pL82 (empty vector) and antiEg transfectants and the percentage of live promastigotes was plotted against time after BLN treatment (Figure 5D). All Tet uninduced parasites were killed upon BLN treatment (data not shown). Treatment of LdEndoG-downregulated parasites (antiEg) with BLN induces a slow non-apoptotic death. While BLN treatment of other parasites induces LdEndoG-mediated DNA degradation and PCD. From Supplementary Information IV, it is evident that mitochondrial membrane permeabilization and ROS generation are considerably reduced in BLN-treated LdEndoG-downregulated parasites. Therefore, the absence of effector endonucleases in antiEg parasites generates a negative feedback response, which suppresses the signaling cascades in the parasites. This hinders BLN-induced DNA degradation and therefore PCD. Viable parasite population exists over a period of $24 \mathrm{~h}$ because the loss of mitochondrial function is prolonged and the parasites undergo a slow nonapoptotic death. DNA fragmentation was estimated over time in BLN-treated transfectants (Figure $5 \mathrm{E}$ ). Tet induction of
antiEg parasites exhibit $75 \%$ reduced extent of DNA fragmentation after $8 \mathrm{~h}$ of BLN treatment. Hence, involvement of LdEndoG in BLN-induced PCD of Leishmania was conclusively elucidated.

LdEndoG forms separate complexes with LdFEN-1 and LdTatD-like nucleases to constitute a DNA 'degradesome' in BLN-treated parasites. Nuclear extracts prepared from wild-type, BLN-treated wild-type and antiEg (BLN treatment was done $24 \mathrm{~h}$ after Tet induction) parasites were immunoprecipitated with anti-LdEndoG. Immunoprecipitated fractions were passed through $\mathrm{Ni}^{2+}$. NTA agarose, as it immobilizes TatD-like nucleases. ${ }^{22}$ The resulting flow-through was electrophoresed and blotted. Immunoblotting with anti-FEN-1 and anti-LdEndoG light up bands corresponding to BLN-treated wild-type parasite fractions only (Figure 6A, a). In wild-type parasites, LdEndoG is localized in mitochondria, whereas for antiEg parasites LdEndoG itself is downregulated, hence antiLdEndoG fails to precipitate LdEndoG from these fractions. DNA zymography using the $\mathrm{Ni}^{2+}-\mathrm{NTA}$ agarose eluates in the presence of $\mathrm{Mg}^{2+}$ and at acidic $\mathrm{pH}$ of 5.3 exhibits distinct nuclease activity in the $39-42 \mathrm{kDa}$ region only for the BLN-treated wild-type parasite fraction (Figure 6A, b). As all properties corresponding to a TatD nuclease were evident, it was assumed to be LdTatD-like nuclease. Presence of nuclease activity at $53 \mathrm{kDa}$ region indicates that LdTatD-like nuclease interacts with LdEndoG and coimmobilizes it.

To elucidate whether LdEndoG, LdFEN-1 and LdTatD-like nuclease interact together or form separate complexes, nuclear extracts from same parasites were immunoprecipitated using anti-FEN-1 and passed through $\mathrm{Ni}^{2+}-\mathrm{NTA}$ agarose. When the flow-through was immunoblotted with anti-FEN-1 itself, bands appear in all three fractions (upper panel, Figure $6 \mathrm{~B}, \mathrm{a}$ ). This indicates that LdFEN-1 is a nuclear protein. Immunoblotting with anti-LdEndoG lights up a band only in the BLN-treated wild-type parasite fraction (lower panel, Figure 6B, a). This shows that BLN treatment induces nuclear translocation of LdEndoG where it forms a complex with LdFEN-1. DNA zymography does not show any nuclease activity with the $\mathrm{Ni}^{2+}-\mathrm{NTA}$ agarose eluate (Figure 6B, b), indicating that LdFEN-1 does not complex with LdTatD-like nuclease and therefore fails to co-immunoprecipitate it.

From immunoprecipitation experiments, it is evident that BLN-induced PCD involves a DNA 'degradesome' of Leishmania comprising LdEndoG/LdFEN-1 and LdEndoG/ LdTatD-like nuclease complexes along with residual LdEndoG, which together carry out DNA degradation. Other nucleases may also have a subtle role in DNA fragmentation.

Extent of DNA fragmentation by the complexes LdEndoG/LdTatD-like nuclease and LdEndoG/LdFEN-1 and residual LdEndoG. The extent of DNA fragmentation carried out by the nucleases of the DNA 'degradesome' was next determined. Activated nuclear extracts (ANEs) prepared $^{23}$ from BLN-treated parasites was the source of parasite nucleases. ${ }^{18}$ Nuclear chromatin isolated ${ }^{24}$ from DU145 cell lines served as the substrate. Incubation of chromatin (C) with ANE causes pronounced DNA 
A

DMSO treated

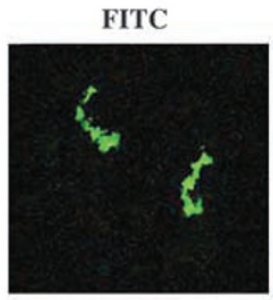

b

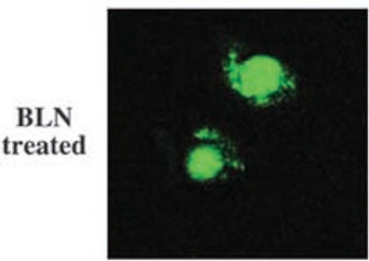

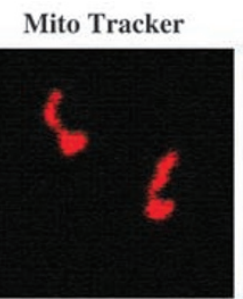

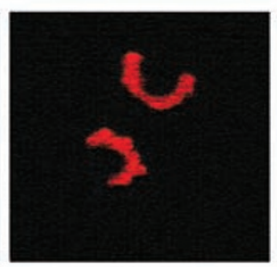

DAPI
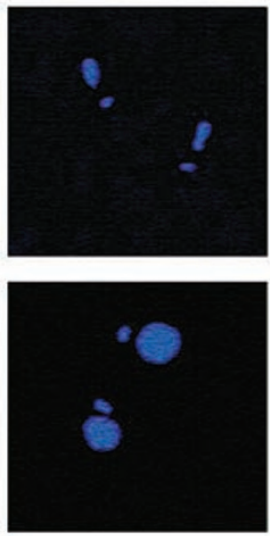
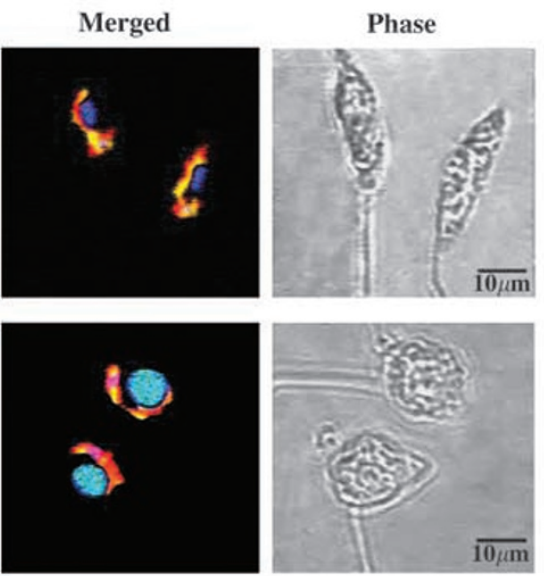

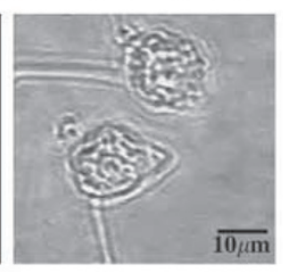

B

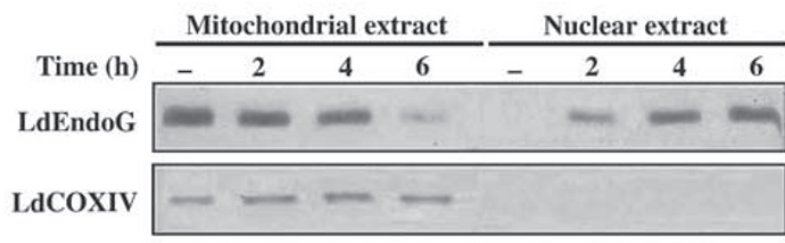

$\begin{array}{llllll}\text { C } & \text { Time (h) } & 12 & 24 & 12 & 24\end{array}$

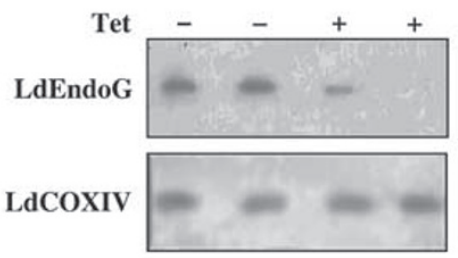

Histone $\mathbf{H 1}$

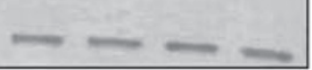

E
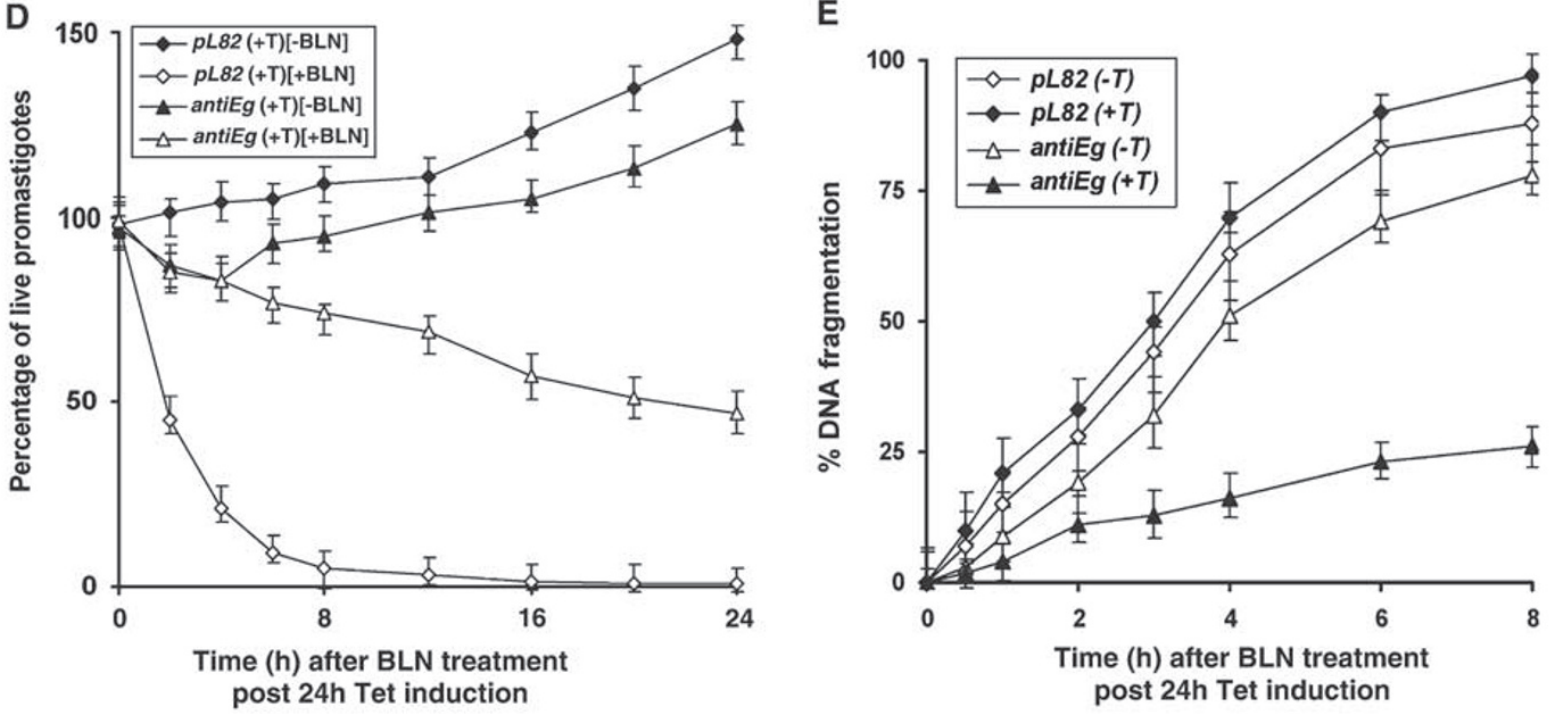

Figure 5 Nuclear translocation of $L d E n d o G$ and viability of $L d E n d o G$ knocked down parasites upon BLN treatment. (A) Parasites were either treated with $0.2 \%$ DMSO (a) or $10 \mu \mathrm{M}$ BLN (b). The FITC panel shows the localization of LdEndoG. DMSO-treated parasites show mitochondrial localization hence merges with MitoTracker, whereas BLN treatment causes nuclear translocation of LdEndoG hence merges with DAPI. (B) Western blot analysis of the mitochondrial and nuclear fractions obtained from BLN-treated parasites at different intervals. Immunoblotting with anti-LdEndoG shows gradual decrease in LdEndoG from the mitochondrial fraction with concomitant increase in the nuclear fraction, anti-COXIV and anti-Histone $\mathrm{H} 1$ served as the loading controls for the mitochondrial and nuclear fractions, respectively. (C) Immunoblot analysis of LdEndoG in Tet uninduced $(-)$ and induced $(+)$ antiEg transfectant parasites at 12 and $24 \mathrm{~h}$ time points. Western blots using anti-COXIV served as loading controls. (D) Transfectants, $p L 82$ and antiEg were Tet induced $(+\mathrm{T})$ for $24 \mathrm{~h}$ and thereafter treated with ( $\diamond$ and $\Delta$, respectively) or without $(\boldsymbol{\Delta}$ and $\boldsymbol{\Lambda}$, respectively) $10 \mu \mathrm{M}$ BLN. Percentage of viable promastigotes was calculated. Values taken in triplicate were averaged and plotted against time. (E) Extent of DNA fragmentation upon BLN treatment of $p L 82(\diamond$ and $\bullet$, respectively) and antiEg ( $\Delta$ and $\boldsymbol{\Delta}$, respectively), transfectants $24 \mathrm{~h}$ after Tet induction. Data represent means \pm S.D., where $n=3$

fragmentation (Figure 7a, lane 2). The flow-through of ANE passed through $\mathrm{Ni}^{2+}-\mathrm{NTA}$ agarose to immobilize out LdEndoG/LdTatD-like nuclease complex (E/T complex) shows partial decrease in DNA fragmentation (lane 3 ). Subsequently, anti-FEN-1 immunoprecipitates out
LdEndoG/LdFEN-1 complex (E/F complex) from above flow-through. The supernatant devoid of $E / T$ and $E / F$ complex exhibited lesser extent of DNA fragmentation (lane 4). Finally, when anti-LdEndoG immunoprecipitates out residual LdEndoG (E) from the above supernatant the 
A

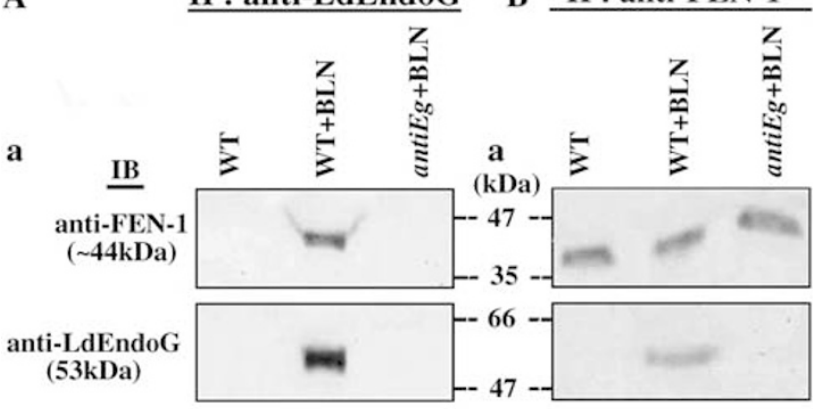

b

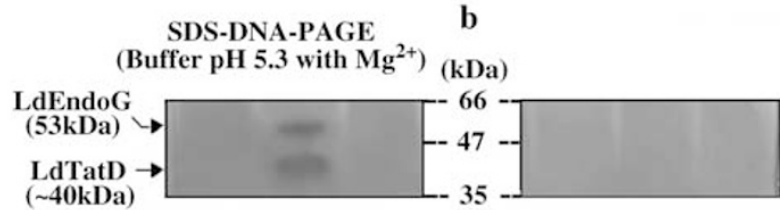

Figure 6 Identification of a DNA 'degradesome' in Leishmania. (A) Nuclear extracts, prepared from wild-type (WT), BLN-treated WT and antiEg parasites, were immunoprecipitated using anti-LdEndoG and passed through $\mathrm{Ni}^{2}{ }^{2}-\mathrm{NTA}$ agarose. (a) Immunoblotting of flow-through with anti-FEN-1 (upper panel) and anti-LdEndoG (lower panel). (b) Eluates from $\mathrm{Ni}^{2+}$-NTA agarose were electrophoresed in SDSDNA-PAGE and incubated in a buffer containing $20 \mathrm{mM}$ Tris-HCl, pH 5.3 and $2 \mathrm{mM}$ $\mathrm{MgCl}_{2}$. (B) Same as (A) except that immunoprecipitation was carried out using antiFEN-1

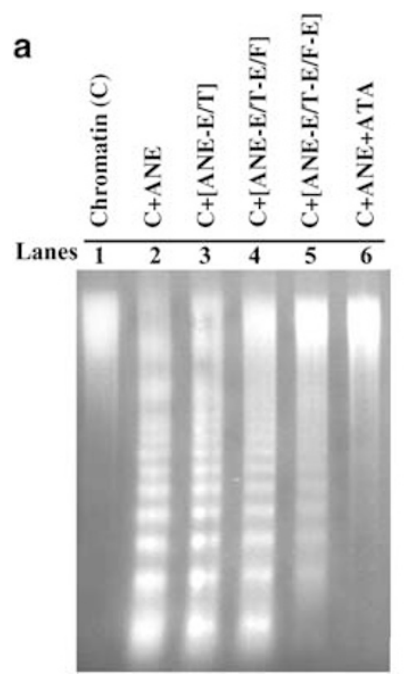

b

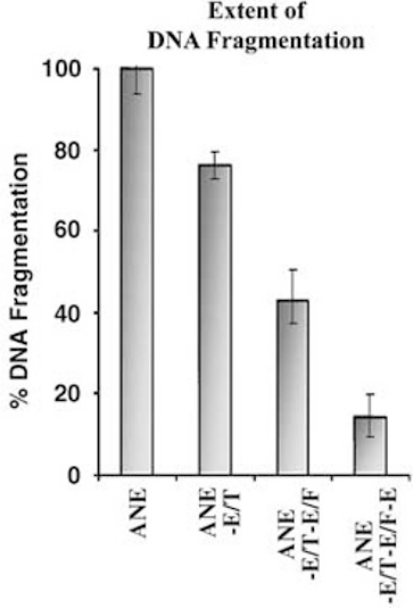

Figure 7 Extent of DNA fragmentation by the components of the DNA 'degradesome'. (a) Chromatin, isolated from DU145 cells served as the substrate. Activated nuclear extracts (ANEs) prepared from BLN-treated parasites contained the DNA 'degradesome'. Isolated chromatin (C) in lane 1 incubated with ANE (lane 2) or ANE devoid of $E / T$ complex (lane 3) or ANE devoid of $E / T$ and $E / F$ complex (lane 4) or ANE devoid of E/T, E/F complex and residual LdEndoG (lane 5). Chromatin was also incubated with ANE in the presence of $50 \mu \mathrm{M}$ ATA. (b) Percentage of DNA fragmentation was obtained using similar fractions as in (a). Values were obtained from the MULTISCAN EX readings at $405 \mathrm{~nm}$. The relative percentage of DNA fragmentation for ANE devoid of $E / T$ complex, $E / T$ and $E / F$ complex and $E / T, E / F$ complex along with residual LdEndoG (with respect to samples treated with whole ANE and normalized to percentage values) was plotted. Data represent means \pm S.D. $(n=3)$

remaining supernatant shows drastically reduced DNA fragmentation (lane 5). ANE failed to fragment chromatin in the presence of ATA (lane 6).
Cell death detection $\mathrm{kit}^{12}$ was used to evaluate the exact share of these complexes in DNA fragmentation. Isolated nuclear chromatin was incubated with the same fractions as above. The percentage of DNA fragmentation by fractions devoid of E/T complex, E/T and E/F complex and both complexes along with residual LdEndoG were 76,43 and $14 \%$, respectively (Figure $7 \mathrm{~b}$ ). Thus $\mathrm{E} / \mathrm{T}$ complex and $\mathrm{E} / \mathrm{F}$ complex, respectively, carry out 24 and $33 \%$, whereas residual LdEndoG carry out another $29 \%$ of total DNA degradation. The rest $14 \%$ is perhaps carried out by $\mathrm{Ca}^{2+} /$ $\mathrm{Mg}^{2+}$-activated nucleases, which are associated with caspase-independent PCD pathways.

\section{Discussion}

PCD of unicellular organisms has been established, ${ }^{2,6,10,13,14}$ but the effector molecules associated with it are yet to be defined. In a post-genomic perspective, rigorous search in the Leishmania genome database fails to identify most of the effector molecules associated with the caspase-dependent PCD pathway but distinctly different homologs may exist that are yet to be identified. Recently metacaspases, which are a completely different class of proteins, have come up as effector molecules in these parasites. ${ }^{15} \mathrm{BLN}$, a plant-derived flavonoid, possesses potent antimicrobial properties. This study shows that BLN induces a caspase-independent PCD pathway in Leishmania by activating LdEndoG to form DNA-degrading complexes with LdFEN-1 and LdTatD-like nucleases.

BLN inhibits bi-subunit topoisomerase IB of Leishmania ${ }^{11}$ by stabilizing the topol-DNA cleavable complex and causes oxidative stress-induced growth arrest of the parasites. There is externalization of phosphatidyl serine, nuclear DNA fragmentation, plasma membrane blebbing and vacuolization. BLN-induced oxidative stress increases intracellular calcium concentration, which concomitantly accumulates in mitochondria. Cation imbalance inside the parasite mitochondria causes its membrane to depolarize. When calcium reaches critical threshold the mitochondrial outer membrane is permeabilized (mediated by VDAC channels ${ }^{20}$ ). There is concomitant inner membrane permeabilization promoted by the permeability transition pore. Resultant generation of ROS boosts up the stress pathway and also causes oxidative DNA lesions. ${ }^{2}$ Besides, disruption of electron transport chain could prevent the role of Bax inhibitor-1 (LmjF24.1190) as a cell death suppressor. ${ }^{25}$ Lipid peroxidation causes release of cytochrome $c$ into the cytosol ${ }^{10}$ along with the effector endonuclease, LdEndoG. ${ }^{3}$ Increased ROS production depletes cellular TSH levels in Leishmania and thereby accelerates growth arrest. ${ }^{10}$ ATA inhibits the effector endonuclease and generates a negative feedback response to dampen the interlinked signaling cascade and reduces the extent of $\Delta \psi_{\mathrm{m}}$, cytochrome $c$ release and ROS production. Besides this, the divalent metal-chelating role of $A T A^{26}$ helps maintain cation homeostasis.

In higher eukaryotes, release of cytochrome $c$ results in 'apoptosome' formation that activates the caspase cascade and thereby CAD. ${ }^{27}$ The negative assays for caspase-like proteins (data not shown) and ineffectiveness of ZVAD-fmk and antipain to prevent DNA degradation indicated the 
activation of a caspase-independent PCD mechanism by BLN. BLN treatment translocates LdEndoG into the nucleus. This perhaps is mediated by cyclophilin $A$, as it efficiently translocates AIF to the nucleus. ${ }^{28}$ Inside the parasite nucleus, $\mathrm{LdEndoG}^{3}$ and $\mathrm{ROS}^{12}$ produce nicked chromatin. Besides, the stabilized topolB-DNA complex generates single and double strand breaks. ${ }^{10}$ These nicked chromatin form the substrate of LdEndoG-assembled DNA 'degradesome' complex.

The GST tag of recombinant GST-LdEndoG (expressed in Rosetta strain) was cleaved using FactorX to obtain recombinant LdEndoG. DNA zymography shows that recombinant LdEndoG has potent nuclease activity, whereas GSTLdEndoG is least active indicating that GST tag has a role similar to the mitochondrial localization signal of LdEndoG pre-protein. Conclusive evidence of its role as an effector molecule in parasite PCD is obtained when BLN fails to induce PCD in LdEndoG-downregulated parasites and they undergo a non-apoptotic death. This perhaps is modulated by alternative oxidase (LmjF36.4380) of mitochondrial inner membrane, which functions in alternate electron transport even when the outer membrane is depolarized. ${ }^{29}$ Subtle permeabilization of mitochondrial outer membrane causes harmless release of cytochrome $c,{ }^{30}$ whereas alternative electron transport functions in the inner membrane.

LdEndoG engages a DNA degradesome inside the activated nuclei of BLN-treated parasites. Nicked chromatin (Figure 8) are substrates of DNA repair enzyme FEN-1 that possesses $5^{\prime}-3^{\prime}$ exonuclease activity as well as gap endonuclease activity. ${ }^{16}$ LdEndoG interacts with LdFEN-1 (E/F complex) and causes mutual conformational changes to shift balance onto cell death and initiate DNA degradation. Onset of PCD lowers intracellular $\mathrm{pH}$, increases intracellular

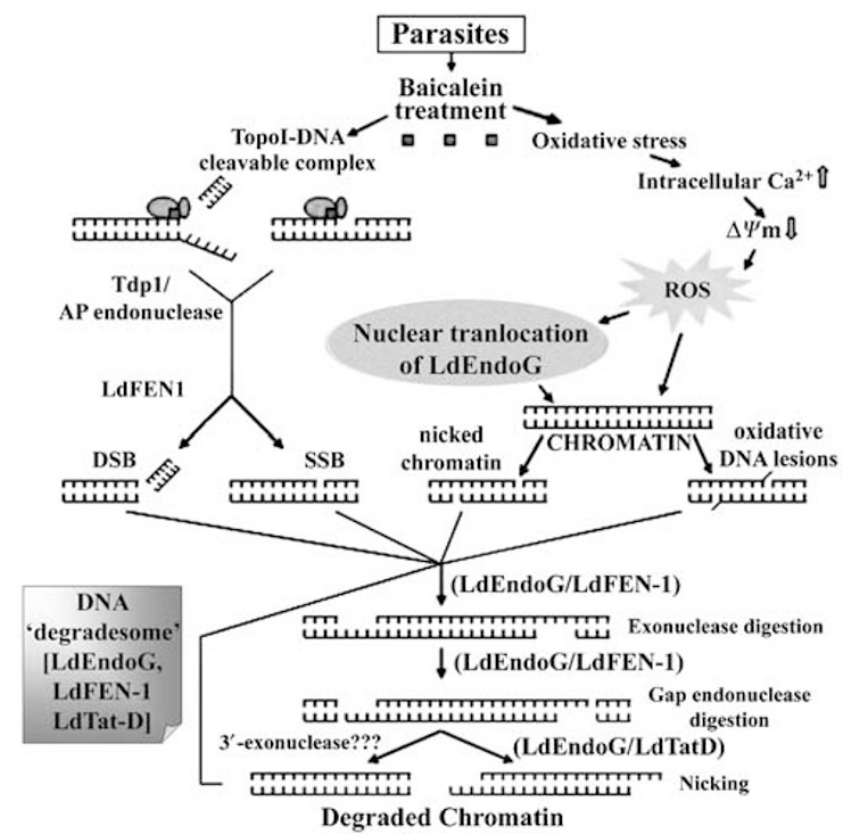

Figure 8 Schematic pathway of BLN-induced caspase-independent programmed cell death in Leishmania involving a DNA 'degradesome' comprising of LdEndoG/LdFEN-1, LdEndoG/LdTatD-like nuclease complexes and residual LdEndoG
$\mathrm{Ca}^{2+}$ pools and reduces cellular $\mathrm{K}^{+}$level inside Leishmania ${ }^{13}$ which thereby activate LdTatD-like nucleases and $\mathrm{Ca}^{2+} / \mathrm{Mg}^{2+}$-dependent nucleases. LdEndoG interacts with LdTatD-like nuclease (E/T complex) to induce its $3^{\prime}$-exonuclease activity. Besides, cyclophilin $A$ also acts as an endonuclease in these conditions. ${ }^{31}$

A recent report identifies EndoG of kinetoplastids as an effector molecule of kinetoplastid PCD pathway ${ }^{32}$ but they fail to conclusively devise the caspase-independent cell death cascade from generation of cellular stress to DNA fragmentation. We for the first time establish a caspase-independent PCD mechanism in Leishmania. In comparison to 'apoptosome' complex of higher eukaryotes, we report a DNA 'degradesome' comprising of the key modulator, LdEndoG along with LdFEN-1 and LdTatD-like nucleases, which serve as 'Atropos' scissors' ${ }^{33}$ for the parasites. The paucity of knowledge in terms of PCD effector molecules in Leishmania is resolved. A better understanding of PCD pathways in Leishmania would help generate genetically modified parasites as promising candidates for live vaccines. Our study on the molecular details of PCD in Leishmania could open new strategies to eliminate parasites without provoking strong immunological reactions in the host. This report on the type of PCD involved and different effector molecules induced is a first step in that direction.

\section{Materials and Methods}

Drug solutions and chemicals used. BLN, CPT, NAC $(20 \mathrm{mM}$ concentration each), CCCP (100 mM), BAPTA-AM $(50 \mathrm{mM})$ and $\mathrm{H}_{2}$ DCFDA $(10 \mathrm{mM})$ were dissolved in $100 \% \mathrm{DMSO}$ and stored at $-20^{\circ} \mathrm{C}$. Antipain $(10 \mathrm{mM})$ and ATA (ammonium salt at $20 \mathrm{mM}$ ) were dissolved in water and stored at $-20^{\circ} \mathrm{C}$.

Strains and parasite culture. Leishmania strain AG83 promastigotes were grown in M199 media (with or without phenol red) supplemented with 10\% FCS at $22{ }^{\circ} \mathrm{C}$. For knockdown studies, the L. tarentolae T7.TR strain (JenaBioscience) was used. ${ }^{34}$ To maintain the genome integrated T7 RNA polymerase and Tet repressor genes, the parasites were cultured in the presence of nourseothricin and hygromycin $(100 \mu \mathrm{g} / \mathrm{ml}$ each).

Cytotoxicity assays. Cytotoxicity of BLN was measured by microscopic counting of viable parasites by Trypan blue exclusion method after treating them with indicated concentrations of the drug. Parasites treated with $0.2 \%$ DMSO served as the control. ${ }^{10}$

Measurement of oxygen consumption. L.donovani AG83 promastigotes $\left(5 \times 10^{6}\right.$ cells $\left./ \mathrm{ml}\right)$ were grown in M199 medium containing $10 \mu \mathrm{M}$ $\mathrm{BLN}$ or $0.2 \%$ DMSO. Cell aliquots were taken at indicated time intervals, harvested and washed with respiration buffer ( $50 \mathrm{mM}$ sucrose, $145 \mathrm{mM} \mathrm{KCl}, 5 \mathrm{mM} \mathrm{NaCl}, 1 \mathrm{mM}$ EDTA, $1 \mathrm{mM} \mathrm{MgCl}_{2}$ and $10 \mathrm{mM}$ sodium phosphate buffer, $\mathrm{pH}$ 7.4) and finally suspended in it. Oxygen uptake was determined with a Clarke-type oxy-electrode having a cell capacity of $2 \mathrm{ml}^{10}$ Calibration of the oxy-electrode was carried out using air-saturated water containing sodium metabisulfite.

Determination of morphological changes characteristic of PCD Double staining with annexinV and PI. Externalization of phosphatidyl serine on the outer membrane of untreated and BLN-treated promastigotes was measured by binding of FITC-annexinV and PI using an FLUOS-annexinV staining $\mathrm{kit}^{10,13}$ (Roche Diagnostics). Cells were visualized under TCS-SP Leica confocal microscope through dual FITC/PI filter set. Flow cytometry was carried out with another set of similarly stained parasites. The gating was done so that the FL-1 channel denotes the mean intensity of FITC-annexinV, whereas the FL-2 channel denotes the mean intensity of $\mathrm{PI}$. The data represented here are a mean of three experiments. 
Study of parasite ultrastructure by transmission electron microscopy. Transmission electron microscopy (TEM) was carried out to visualize the ultrastructure of BLN-treated and untreated parasites. ${ }^{10}$ Samples were prepared accordingly and thin sections were cut using a Du-point diamond knife in an LKB Ultramicrotome, stained on copper grids using uranyl acetate and lead acetate for 10-15 min and examined under JEOL 100CX TEM.

\section{Determining PCD-associated physiological changes}

Measurement of mitochondrial membrane potential. Mitochondrial membrane potential was measured using $\mathrm{BD}$ mitosensor reagent following the manufacturer's protocol. ${ }^{13}$ Parasites were treated with BLN $(5$ and $10 \mu \mathrm{M})$ alone or with $10 \mu \mathrm{M}$ BLN after pretreatment with NAC $(20 \mathrm{mM})$, BAPTA-AM $(25 \mu \mathrm{M})$ or ATA $(50 \mu \mathrm{M})$. Parasites treated with $0.2 \%$ DMSO or with the uncoupler CCCP $(1 \mu \mathrm{M})$ served as controls. After different treatments, parasites were harvested and washed with $1 \times$ PBS and thereafter incubated with BD mitosensor reagent $(5 \mu \mathrm{g} / \mathrm{ml})$ at $28^{\circ} \mathrm{C}$ for $1 \mathrm{~h}$ followed by flow cytometry analysis. The FL-1 channel indicated the mean green fluorescence intensity. The flow cytometric data represented here are a mean of three experiments.

Detection of cytochrome $c$ release. $L$. donovani promastigotes $\left(1 \times 10^{7}\right.$ cells $/ \mathrm{ml}$ ) were treated with $10 \mu \mathrm{M} \mathrm{BLN}$ for indicated time periods. Equal numbers of parasites were pretreated separately for $2 \mathrm{~h}$ with NAC, BAPTA-AM, ATA, zVAD-fmk $(25 \mu \mathrm{M})$, antipain $(2 \mu \mathrm{M})$ or cyclosporine $\mathrm{A}(10 \mu \mathrm{M})$ and thereafter treated with $\mathrm{BLN}$ $(10 \mu \mathrm{M})$. Treated and untreated parasites were harvested and washed twice with $1 \times$ PBS and suspended in cell fractionation buffer (ApoAlert cell fractionation kit) and homogenized. ${ }^{10}$ After the separation of cytosolic and mitochondrial fractions, $40 \mu \mathrm{g}$ proteins from each fraction were electrophoresed in different sets of $10 \%$ SDS-PAGE. The proteins were transferred to nitrocellulose membrane. One from each fraction was immunoblotted with rabbit polyclonal anti-human cytochrome $c$ antibody (Santa Cruz). The other blot of the cytosolic fraction was probed with mouse polyclonal anti-human $\beta$-tubulin antibody (Santa Cruz), whereas the other blot of the mitochondrial fraction was probed with rabbit polyclonal anti-leishmanial COXIV antibody ${ }^{10}$ as loading controls. The membranes were next probed with HRPconjugated anti-rabbit or anti-mouse secondary antibody followed by addition of the $\mathrm{DAB} / \mathrm{H}_{2} \mathrm{O}_{2}$ substrate.

Measurement of ROS. Intracellular ROS levels were measured in BLN-treated and untreated parasites. Promastigotes $\left(2 \times 10^{7} \mathrm{cells} / \mathrm{ml}\right)$ were treated with $10 \mu \mathrm{M}$ BLN alone or after pretreatment with NAC or ATA. Parasites treated with $0.2 \%$ DMSO served as controls. After different treatments, parasites were washed and resuspended in $500 \mu \mathrm{l}$ of M199 (without phenol red) and loaded with a cell permeant dye $\mathrm{H}_{2}$ DCFDA for $1 \mathrm{~h}^{13}$ The green fluorescence of DCF was measured at $530 \mathrm{~nm}$ using a spectrofluorimeter. Another set of similarly treated parasites was observed under the confocal microscope.

\section{DNA fragmentation assays}

DNA ladder assay. Genomic DNA was isolated from the parasites $\left(5 \times 10^{6}\right.$ cells $/ \mathrm{ml}$ ) after different treatments using an apoptotic DNA ladder kit ${ }^{10}$ (Roche Diagnostics). The DNA was quantified and equivalent amount of DNA was electrophoresed in a $1.5 \%$ agarose gel at $75 \mathrm{~V}$ for $2 \mathrm{~h}$ and thereafter stained with $\mathrm{EtBr}$ and photographed under UV illumination.

TUNEL assay. The extent of fragmentation in nuclear and kinetoplast DNA was visualized through TUNEL assay. ${ }^{10}$ The promastigotes were fixed with $2 \%$ paraformaldehyde after various treatments. Next the parasites were permeabilized using $0.2 \%$ Triton $\mathrm{X}-100$ for $5 \mathrm{~min}$ and thereafter layered with TdT reaction mixture containing fluorescein-dUTP for $1 \mathrm{~h}$ at $37^{\circ} \mathrm{C}$ according to the manufacturer's protocol (ApoAlert DNA fragmentation assay kit). The parasites were counterstained with $\mathrm{PI}$ and visualized under a TCS-SP Leica confocal microscope through dual pass FITC/PI filter set. The percentage of TUNELpositive cells was calculated for 200 parasites as seen under the microscope. The values represented are a mean of three independent experiments.

ELISA-based estimation of DNA fragmentation. An estimate of the extent of DNA fragmentation after drug treatments and in the presence of various inhibitors of PCD was carried out using the cell death detection ELISA kit ${ }^{12}$ (Roche Biochemicals). Promastigote samples $\left(5 \times 10^{6} \mathrm{cells} / \mathrm{ml}\right)$ were collected at 2-h intervals and the histone-associated DNA fragments (mononucleosome and oligonucleosome) were detected using the manufacturer's protocol. DNA fragmentation was estimated by spectrophotometric measurement of microtiter plates in a Thermo MULTISCAN EX plate reader at $405 \mathrm{~nm}$. The relative percentage (with respect to samples treated with micrococcal nuclease and normalized to percentage values) was plotted as units of time.
Cell fractionation. Nuclear/kinetoplast $(\mathrm{N} / \mathrm{K})$ fraction was prepared by lysing parasites with $140 \mathrm{mM} \mathrm{NaCl}, 1.5 \mathrm{mM} \mathrm{MgCl} 2,10 \mathrm{mM}$ Tris-HCl, pH 8.6, 0.5\% NP-40 and protease inhibitors. ${ }^{32}$ After 10 min incubation, it was centrifuged at $6000 \times \mathrm{g}$ for $5 \mathrm{~min}$ at $4{ }^{\circ} \mathrm{C}$. The supernatant served as the cytosolic fraction, whereas the pellet was the $\mathrm{N} / \mathrm{K}$ fraction (as both share more or less similar mass for kinetoplastids). For immunoblotting analysis, the nuclear extract was prepared by resuspending the $N / K$ fraction in the same buffer with $0.25 \mathrm{mg} / \mathrm{ml}$ digitonin and $100 \mathrm{U}$ of DNasel. It was kept for $15 \mathrm{~min}$ at room temperature. Thereafter it was centrifuged at $10000 \times g$ for $10 \mathrm{~min}$ at $4{ }^{\circ} \mathrm{C}$. The supernatant served as the nuclear extract. The mitochondrial pellet was resuspended in the same buffer containing $1 \mathrm{mg} / \mathrm{ml}$ digitonin and $0.2 \%$ Triton X-100. After $10 \mathrm{~min}$ incubation at room temperature, it was centrifuged at $12000 \times g$ for $10 \mathrm{~min}$ at $4{ }^{\circ} \mathrm{C}$ to obtain the mitochondrial fraction.

Cloning and purification of Leishmania EndoG. The EndoG gene in Leishmania represents an ORF, LmjF10.0610 in the L. major genome database. Sense primer $5^{\prime}$-CGGGATCCATGATCGCCCGGCTGCTCGGCGCA-3' and the antisense primer $5^{\prime}$-CGCTCGAGTCAGCGTCGCTCTGCCTGGTCGAT-3' were used to PCR amplify the LdEndoG gene from the CDNA pool of $L$. donovani AG83 strain. It was cloned in the BamHI/Xhol site of the vector pGEX-4T. It was transformed into $E$. coli Rosetta strain. Thereafter, 1 I of the culture was grown to $\mathrm{OD}_{600}=0.5$ and induced with $0.3 \mathrm{mM}$ IPTG for $3 \mathrm{~h}$ at $25^{\circ} \mathrm{C}$. Proteins were lysozyme/sonicated and purified using GST-sepharose 4B. To purify GST-LdEndoG the bound proteins were eluted using reduced glutathione, whereas to purify recombinant $L d E n d o G$ elution was carried out with FactorX in PBS. For the eluted fraction containing FactorX, FactorX removal kit (Pierce) was used.

DNA zymography. Direct nuclease activity was observed using the SDS-DNA PAGE technique. ${ }^{18}$ Briefly, $20 \mu \mathrm{g} / \mathrm{ml}$ of calf thymus DNA was added in a $10 \%$ acrylamide separating gel. The recombinant GST-LdEndoG and LdEndoG were loaded in increasing concentrations from 25 to $200 \mathrm{nM}$ and electrophoresed. Thereafter the gel was washed in distilled water for $30 \mathrm{~min}$ and suspended in renaturation buffer ( $50 \mathrm{mM}$ Tris- $\mathrm{HCl}, \mathrm{pH} 7.5,2 \mathrm{mM} \mathrm{MgCl}$, $0.5 \mathrm{mM}$ EDTA, $1 \mathrm{mM}$ DTT and $5 \%$ glycerol) containing $200 \mu \mathrm{g} / \mathrm{ml}$ of EtBr overnight. For the SDS-DNA-PAGE of LdTatD-like nucleases, the gels were washed in distilled water soaked in renaturation buffer for $1 \mathrm{~h}$ and thereafter suspended in low pH buffer (20 mM Tris$\mathrm{HCl}, \mathrm{pH} \mathrm{5.3,2} \mathrm{mM} \mathrm{MgCl}, 1 \mathrm{mM} \mathrm{DTT}$ and $5 \%$ glycerol).

DNase assay using plasmid DNA and isolated nuclei. Purified LdEndoG was mixed with pGEM4Z plasmid DNA or nuclei isolated from DU145 cells. ${ }^{5}$ For preparing nuclei, $2 \times 10^{7}$ cells were washed with ice-cold PBS and suspended in $400 \mu$ l buffer A (10 mM HEPES, pH 7.9, $10 \mathrm{mM} \mathrm{KCl}, 1.5 \mathrm{~mm} \mathrm{MgCl}$, $0.34 \mathrm{M}$ sucrose, $10 \%$ glycerol, $1 \mathrm{mM}$ DTT and protease inhibitor cocktail). Triton $\mathrm{X}-100$ was added to a final concentration of $0.1 \%$ and cells were incubated in ice for $10 \mathrm{~min}$. It was centrifuged at $1300 \times g$ for $5 \mathrm{~min}$ at $4^{\circ} \mathrm{C}$ to obtain the nuclear pellet. The DNase assay was carried out in a buffer containing $50 \mathrm{mM}$ Tris- $\mathrm{HCl}, \mathrm{pH} 7.4$, $1 \mathrm{mM} \mathrm{MgCl}, 10 \mathrm{mM} \mathrm{KCl}$ and $0.5 \mathrm{mM} \mathrm{DTT}$. ATA ( 15 and $50 \mu \mathrm{M}$ ) was used to inhibit endonuclease activity while $\mathrm{H}_{2} \mathrm{O}_{2}(5 \mathrm{mM})$ was added to mimic oxidative stress condition. ${ }^{5}$

Immunofluorescence. Parasites were treated with $0.2 \%$ DMSO or $10 \mu \mathrm{M}$ BLN for $3 \mathrm{~h}$ following which they were washed with M199 (without phenol red) and layered on poly-L-lysine-coated cover slips. They were fixed with $4 \%$ paraformaldehyde and blocked using 5\% BSA in M199 (without phenol red) containing $0.5 \mathrm{mg} / \mathrm{ml}$ digitonin. Next it was incubated with anti-LdEndoG antibody (antibody was raised against LdEndoG in rabbit and tested for cross-reactivity) for $2 \mathrm{~h}$ followed by FITC-conjugated anti-rabbit secondary antibody for $1 \mathrm{~h}$. During secondary antibody incubation, parasites were also incubated with MitoTracker Red. Thereafter the cover slips were mounted under a confocal microscope using UltraCruz mounting medium containing appropriate amounts of DAPI and antifade solution.

Parasite growth in LdEndoG-downregulated parasites. Wild-type LdEndoG was downregulated using the conditional antisense ${ }^{34}$ approach as stated in Supplementary information III. BLN treatment was carried out after $24 \mathrm{~h}$ of tetracycline induction in the antiEg transfectants, whereas the $p L 82$ transfectants served as the empty vector controls. Live promastigotes were calculated at given time intervals. Three sets of experiments were carried out and the values were averaged and plotted. 
Immunoblotting and immunoprecipitation. Cell fractionation was carried out as indicated earlier. Equal amounts of proteins from respective fractions as indicated and in the required number of sets were electrophoresed in $10 \%$ SDS-PAGE and transferred to nitrocellulose. Thereafter they were blocked using 5\% BSA and immunoblotted using rabbit polyclonal anti-LdEndoG antibody. For loading controls corresponding to mitochondrial and nuclear fractions, similar blots were probed with rabbit polyclonal anti-leishmania COXIV antibody and goat polyclonal anti-human histone H1 antibody (Santa Cruz) followed by HRPconjugated respective secondary antibodies.

Nuclear extracts were prepared from wild-type, BLN-treated wild-type and antiEg parasites ${ }^{23}$ and precleared using proteinG-sepharose beads. Immunoprecipitation was next carried out using Protein-G immunoprecipitation kit (Sigma) and rabbit polyclonal anti-LdEndoG and goat polyclonal anti-human FEN-1 antibody following the manufacturer's protocol. When required the nuclear extracts were incubated with $\mathrm{Ni}^{2+}{ }_{-} \mathrm{NTA}$ agarose prior to immunoprecipitation to immobilize the LdTatD-like nucleases. ${ }^{22}$

Estimating chromatin fragmentation using ANE. The extent to which LdEndoG, LdFEN-1 and LdTatD-like nucleases contributed to chromatin fragmentation in the activated nuclei of BLN-treated parasites was estimated using the cell death detection ELISA kit. ${ }^{12}$ Chromatin was isolated from DU145 cells ${ }^{24}$ and treated with the ANE from BLN-treated parasites. ${ }^{23}$ Briefly $2 \times 10^{7}$ cells were washed twice in ice-cold $1 \times$ PBS. Thereafter the cells were suspended in $400 \mu \mathrm{l}$ of buffer A (10 mM HEPES, pH 7.9, $10 \mathrm{mM} \mathrm{KCl}, 1.5 \mathrm{mM} \mathrm{MgCl}_{2}, 0.34 \mathrm{M}$ sucrose, $10 \%$ glycerol, $1 \mathrm{mM}$ DTT and protease inhibitor cocktail). Triton X-100 was added to a final concentration of $0.1 \%$ and cells were incubated in ice for $10 \mathrm{~min}$. It was centrifuged at $1300 \times g$ for $5 \mathrm{~min}$ at $4{ }^{\circ} \mathrm{C}$ and the nuclear pellet was obtained. The pellet was washed once with buffer $A$ and suspended in $200 \mu$ l buffer $B(3 \mathrm{mM}$ EDTA, $0.2 \mathrm{mM}$ EGTA, $1 \mathrm{mM}$ DTT and protease inhibitors) for $30 \mathrm{~min}$ at $4{ }^{\circ} \mathrm{C}$. Chromatin pellet was obtained by centrifugation at $1700 \times g$ for 5 min at $4{ }^{\circ} \mathrm{C}$. The pellet was rigorously washed 5-6 times with $10 \mathrm{ml}$ each of ice-cold $1 \times$ PBS containing protease inhibitor cocktail to remove all traces of EDTA and EGTA, which could hamper DNA fragmentation.

ANEs were prepared from $10^{7}$ parasites after treating them with $10 \mu \mathrm{M}$ $\mathrm{BLN}$ for $3 \mathrm{~h}^{23}$ Thereafter parasites were washed with $1 \times \mathrm{PBS}$ and resuspended in buffer C (10 mM HEPES, pH 7.8, $15 \mathrm{mM} \mathrm{KCl}, 2 \mathrm{mM} \mathrm{MgCl}$, $1 \mathrm{mM}$ EDTA, $1 \mathrm{mM}$ PMSF and $1 \mathrm{mM}$ DTT). After $10 \mathrm{~min}$ incubation on ice, the parasites were mixed and centrifuged for $5 \mathrm{~min}$ at $1000 \times \mathrm{g}$. The supernatants were removed, and the pellets were resuspended in buffer C supplemented with $0.2 \% \mathrm{NP}-40$ and incubated on ice for $5 \mathrm{~min}$. After centrifugation, the nuclear pellets were resuspended in buffer $\mathrm{C}$, and $4 \mathrm{M} \mathrm{KCl}$ was added dropwise until the $\mathrm{KC}$ concentration was $0.4 \mathrm{M}$. The nuclei were incubated for $5 \mathrm{~min}$ at $4{ }^{\circ} \mathrm{C}$ and then centrifuged at $14000 \times g$ to obtain the supernatant as the ANE. LdTatD-like nuclease was removed from ANE by incubating it with $\mathrm{Ni}^{2+}$-NTA agarose. LdFEN1 and $L d E n d o G$ were sequentially removed from the flow-through using respective antibodies and Protein-A sepharose beads. The extent of fragmentation was calculated using cell death detection ELISA kit. DNA fragmentation ${ }^{12}$ induced by whole ANE was taken as the control. On this basis, the percentage DNA degradation induced by ANE progressively devoid of LdTatD-like nuclease, LdFEN1 and LdEndoG was estimated. Values were taken in triplicate, averaged and plotted.

Acknowledgements. We are grateful to Professor S Roy, Director, IICB, for his interest in this work. We thank Professor GAM Cross for gifting the Leismania transfection vectors. We thank Arunima Biswas for her help in flow cytometry. This study was supported by the grant from Department of Biotechnology, Government of India (BT/PR6399/BRB/10/434/05) to HKM. SBD was supported by a Senior Research Fellowship from CSIR, Government of India.

1. Nguewa PA, Fuertes MA, Valladares B, Alonso C, Pérez JM. Programmed cell death in trypanosomatids: a way to maximize their biological fitness? Trends Parasitol 2004; 20: 375-380.

2. Ameisen JC. On the origin, evolution, and nature of programmed cell death: a timeline of four billion years. Cell Death Differ 2002; 9: 367-393.

3. Li LY, Luo $X$, Wang $X$. Endonuclease $G$ is an apoptotic DNase when released from mitochondria. Nature 2001; 412: 95-99.
4. Widlak $P$, Garrard WT. Discovery, regulation, and action of the major apoptotic nucleases DFF40/CAD and endonuclease G. J Cell Biochem 2005; 94: 1078-1087.

5. Ishihara $Y$, Shimamoto $N$. Involvement of endonuclease $G$ in nucleosomal DNA fragmentation under sustained endogenous oxidative stress. J Biol Chem 2006; 281: $6726-6733$

6. Debrabant A, Nakhasi $H$. Programmed cell death in trypanosomatids: is it an altruistic mechanism for survival of the fittest? Kinetoplastid Biol Dis 2003; $2: 7$.

7. Bosedasgupta S, Ganguly A, Das BB, Roy A, Khalkho NV, Majumder HK. The large subunit of Leishmania topoisomerase I functions as the 'molecular steer' in type IB topoisomerase. Mol Microbiol 2008; 67: 31-46.

8. Sordet O, Khan QA, Kohn KW, Pommier Y. Apoptosis induced by topoisomerase inhibitors. Curr Med Chem Anticancer Agents 2003; 3: 271-290.

9. Hanson CJ, Bootman MD, Roderick HL. Cell signalling: IP3 receptors channel calcium into cell death. Curr Biol 2004; 14: R933-R935.

10. Sen N, Das BB, Ganguly A, Mukherjee T, Tripathi G, Bandyopadhyay S et al. Camptothecin induced mitochondrial dysfunction leading to programmed cell death in unicellular hemoflagellate Leishmania donovani. Cell Death Differ 2004; 11: 924-936.

11. Das BB, Sen N, Roy A, Dasgupta SB, Ganguly A, Mohanta BC et al. Differential induction of Leishmania donovani bi-subunit topoisomerase I-DNA cleavage complex by selected flavones and camptothecin: activity of flavones against camptothecin-resistant topoisomerase I. Nucleic Acids Res 2006; 34: 1121-1132.

12. Ganguly A, Das B, Roy A, Sen N, Dasgupta SB, Mukhopadhayay S et al. Betulinic acid, a catalytic inhibitor of topoisomerase I, inhibits reactive oxygen species-mediated apoptotic topoisomerase I-DNA cleavable complex formation in prostate cancer cells but does not affect the process of cell death. Cancer Res 2007; 67: 11848-11858.

13. Mukherjee SB, Das M, Sudhandiran G, Shaha $\mathrm{C}$. Increase in cytosolic $\mathrm{Ca}^{2+}$ levels through the activation of non-selective cation channels induced by oxidative stress causes mitochondrial depolarization leading to apoptosis-like death in Leishmania donovani promastigotes. J Biol Chem 2002; 277: 24717-24727.

14. Ambit A, Fasel N, Coombs GH, Mottram JC. An essential role for the Leishmania major metacaspase in cell cycle progression. Cell Death Differ 2008; 15: 113-122.

15. Lee N, Gannavaram S, Selvapandiyan A, Debrabant A. Characterization of metacaspases with trypsin-like activity and their putative role in programmed cell death in the protozoan parasite Leishmania. Eukaryot Cell 2007; 6: 1745-1757.

16. Parrish JZ, Yang C, Shen B, Xue D. CRN-1, a Caenorhabditis elegans FEN-1 homologue, cooperates with CPS-6/EndoG to promote apoptotic DNA degradation. EMBO J 2003; 22 : 3451-3460

17. Qiu J, Yoon JH, Shen B. Search for apoptotic nucleases in yeast: role of Tat-D nuclease in apoptotic DNA degradation. J Biol Chem 2005; 280: 15370-15379.

18. Zangger $\mathrm{H}$, Mottram JC, Fasel N. Cell death in Leishmania induced by stress and differentiation: programmed cell death or necrosis? Cell Death Differ 2002; 9: 1126-1139.

19. Aminian M, Sivam S, Lee CW, Halperin SA, Lee SF. Expression and purification of a trivalent pertussis toxin-diphtheria toxin-tetanus toxin fusion protein in Escherichia coli. Protein Expr Purif 2007; 51: 170-178.

20. Zamzami N, Larochette N, Kroemer G. Mitochondrial permeability transition in apoptosis and necrosis. Cell Death Differ 2005; 12: 1478-1480.

21. Van Loo G, Saelens X, van Gurp M, MacFarlane M, Martin SJ, Vandenabeele P. The role of mitochondrial factors in apoptosis: a Russian roulette with more than one bullet. Cell Death Differ 2002; 9: 1031-1042.

22. Wexler M, Sargent F, Jack RL, Stanley NR, Bogsch EG, Robinson C et al. TatD is a cytoplasmic protein with DNase activity. No requirement for TatD family proteins in secindependent protein export. J Biol Chem 2000; 275: 16717-16722.

23. Cao G, Pei W, Lan J, Stetler RA, Luo Y, Nagayama T et al. Caspase-activated DNase/DNA fragmentation factor 40 mediates apoptotic DNA fragmentation in transient cerebral ischemia and in neuronal cultures. J Neurosci 2001; 21: 4678-4690.

24. Wysocka J, Reilly PT, Herr W. Loss of HCF-1-chromatin association precedes temperature-induced growth arrest of tsBN67 cells. Mol Cell Biol 2001; 21: 3820-3829.

25. Oshima R, Yoshinaga $\mathrm{K}$, Ihara-Ohori $\mathrm{Y}$, Fukuda R, Ohta A, Uchimiya $\mathrm{H}$ et al. The Bax inhibitor-1 needs a functional electron transport chain for cell death suppression. FEBS Lett 2007; 581: 4627-4632.

26. Sharma RK, Garg BS, Kurosaki H, Goto M, Otsuka M, Yamamoto T et al. Aurine tricarboxylic acid, a potent metal-chelating inhibitor of NFkappaB-DNA binding. Bioorg Med Chem 2000; 8: 1819-1823

27. Bao Q, Shi Y. Apoptosome: a platform for the activation of initiator caspases. Cell Death Differ 2007; 14: 56-65.

28. Zhu C, Wang X, Deinum J, Huang Z, Gao J, Modjtahedi N et al. Cyclophilin A participates in the nuclear translocation of apoptosis-inducing factor in neurons after cerebral hypoxiaischemia. Exp Med 2007; 204: 1741-1748.

29. Williams S, Saha L, Singha UK, Chaudhuri M. Trypanosoma brucei: differential requirement of membrane potential for import of proteins into mitochondria in two developmental stages. Exp Parasitol 2008; 118: 420-433.

30. Von Ahsen O, Waterhouse NJ, Kuwana T, Newmeyer DD, Green DR. The 'harmless' release of cytochrome c. Cell Death Differ 2000; 7: 1192-1199. 
31. Montague JW, Gaido ML, Frye C, Cidlowski JA. A calcium-dependent nuclease from apoptotic rat thymocytes is homologous with cyclophilin. Recombinant cyclophilins A, B and C have nuclease activity. J Biol Chem 1994; 269: 18877-18880.

32. Gannavaram S, Vedvyas C, Debrabant A. Conservation of the pro-apoptotic nuclease activity of endonuclease $G$ in unicellular trypanosomatid parasites. J Cell Sci 2008; 121: 99-109.
33. Deponte M. In search of atropos' scissors: severing the life-threads of Plasmodium. In: Perez-Martin JM (ed). Programmed Cell Death in Protozoa. Landes Bioscience, Texas, USA, 2008: 91-96.

34. Bosedasgupta S, Das BB, Sengupta S, Ganguly A, Roy A, Tripathi G, et al. Amino acids 39-456 of the large subunit and 210-262 of the small subunit constitute the minimal functionally interacting fragments of the unusual heterodimeric topoisomerase IB of Leishmania. Biochem J 2008; 409: 481-489.

Supplementary Information accompanies the paper on Cell Death and Differentiation website (http://www.nature.com/cdd) 